\title{
Extra Biliary Complications of Laparoscopic Cholecystectomy: A Retrospective Analysis in a Tertiary Care Hospital, Rajshahi, Bangladesh Md. Sofi Ullah ${ }^{1 *}$, Ashrafun Nesa ${ }^{2}$
}

${ }^{1}$ Assistant professor, Department of Surgery, OSD-DGHS attached Rajshahi Medical College, Rajshahi, Bangladesh

${ }^{2}$ Indoor Medical Officer, Rajshahi Medical College Hospital, Rajshahi, Bangladesh

DOI: $10.36347 /$ sjams.2020.v08i06.036

| Received: 15.06.2020 | Accepted: 22.06.2020 | Published: 30.06.2020

*Corresponding author: Dr. Md. Sofi Ullah

Abstract

Original Research Article

Background: Laparoscopic cholecystectomy delivers a safer and effective treatment for the patients with symptomatic gallstones and has become the treatment of choice for many patients. In generally complications that occur with laparoscopic cholecystectomy, including bile duct injury, bile leaks, bleeding, and bowel injury, results in part from patient selection, surgical inexperience, and the technical constraints that are inherent to the minimally invasive approach. We have conducted this study to dig out the extra biliary complications of laparoscopic cholecystectomy. Aim of the study: The aim of this study was to evaluate the extra biliary complications of laparoscopic cholecystectomy. Methods: This was a retrospective analysis of extra-biliary complications and was conducted in the Department of -Surgery, Rajshahi Medical College Hospital, Rajshahi, Bangladesh during the period from January 2019 to December 2019. The study population included all the patients with symptomatic gallstone disease in whom laparoscopic cholecystectomy was performed. The extra-biliary complications were divided into two major categories: (i) Procedure related and (ii) Access related. Result: In this study we found the highest $1.86 \%$ participants were with port side bleeding and nearest $0.53 \%$ were with retained stones in port (Sepsis),. Then $0.27 \%, 0.53 \%, 0.27 \%$ and another $0.27 \%$ participants were with small bowel laceration sub-cutaneous emphysema, small bowel puncture and ascending colon laceration respectively. On the other hand the highest $2.13 \%$ participants were with bleeding through cystic artery and $0.80 \%, 0.53 \% 1.60 \%, 0.27 \%$ and $1.86 \%$ participants were with sub-capsular liver hematoma, duodenal perforation, bleeding from Gallbladder bed, colon perforation and stones spillage in peritoneal cavity respectively. In post-operative complications, we found pyoperitoneum 2(0.53\%) and hemorrhage (Secondary, Reactionary) 4(1.06\%). Conclusion: Through this study we observed that major extra-biliary complications are as frequent as the biliary complications and can be life-threatening. On the other hand an early diagnosis is critical to their management. The findings may be helpful in further similar studies.

Keywords: Extra Biliary, Complications, Laparoscopic cholecystectomy.

Copyright @ 2020: This is an open-access article distributed under the terms of the Creative Commons Attribution license which permits unrestricted use, distribution, and reproduction in any medium for non-commercial use (NonCommercial, or CC-BY-NC) provided the original author and source are credited.

\section{INTRODUCTION}

In generally complications that occur with laparoscopic cholecystectomy, including bile duct injury, bile leaks, bleeding, and bowel injury, results in part from patient selection, surgical inexperience, and the technical constraints that are inherent to the minimally invasive approach. We have conducted this study to dig out the extra biliary complications of laparoscopic cholecystectomy. It is said that, laparoscopic cholecystectomy is the standard of hematoma, duodenal perforation, bleeding from care management modality for the treatment of gall bladder bed, spillage of stones in the peritoneal cholelithiasis. Though many modern innovation are cavity and bleeding through cystic artery [1]. Though brought in treating cholelithiasis like SILS (single the frequency of these complications may be incision laparoscopic cholecystectomy) and hybrid reduced like access related, but still not much cholecystectomy, the conventional laparoscopic change in the frequency has occurred even if the cholecystectomy has the proven safely and best laparoscopic cholecystectomy is performed by a cosmetic results [2]. The incidence of complications skilled laparoscopic surgeon [3]. Laparoscopic cholecystectomy is considered superior to open cholecystectomy in terms of morbidity, cosmesis and rate of complications [4]. There are, however, other studies which report an increased rate of complications during laparoscopic cholecystectomy compared to open cholecystectomy [4]. Biliary complications are reported in many studies [5]. The extra-biliary complications do occur with almost the same frequency and severity but tend to be under-reported in the literature [6]. The extra- 
biliary complications can be access-related or procedure-related. Different techniques of abdominal access are described but none has been found to be superior in terms of preventing access-related injuries [7]. Although these complications are not as common as they were in the past, but is still a major source of morbidity associated with laparoscopic cholecystectomy. In a study, Fuller et al.[8] reported laparoscopic cholecystectomy as a procedure most frequently associated with both fatal and non-fatal trocar-related injuries. We report extra-biliary complications in this study with emphasis on their incidence, severity and management. The major objective of this study was to evaluate the extra biliary complications of laparoscopic cholecystectomy.

\section{OBJECTIVES \\ General Objective}

- To evaluate the extra biliary complications of laparoscopic cholecystectomy.

\section{Specific Objective}

- To assess the convulsion ratio to open cholecystectomy among the cases.

\section{Methodology \& Materials}

This was a retrospective analytical study conducted on 376 patients in whom laparoscopic cholecystectomy was performed in the in the Department of -Surgery, Rajshahi Medical College Hospital, Rajshahi,, Bangladesh during the period from January 2019 to December 2019. The cases were operated upon by 4 surgeons with different levels of experience. The study population included all the patients with symptomatic gallstone disease regardless of their age and gender. The intervention was approved by the ethical committee of the mentioned hospital. All the patients were operated by the classical four-port technique while a few amendments were made according to the situation, such as placing an additional port etc. In 107 cases, pneumoperitoneum was created using a Verress needle and in 269 , by a technique of direct trocar insertion. The choice of method for creation of pneumoperitoneum was solely decided by the operating surgeon consulting with the respective patients. Details of each patient were recorded on a predesigned format. The complications were divided into access-related complications and procedure-related complications. The results were analyzed statically using SPSS version 20 and displayed in several tables.

\section{RESULT}

In this study among total 376 participants 32 were male which $8.51 \%$ was and the rest 344 were female which were $91.49 \%$. Among them $7.18 \%$, $20.48 \%, 52.66 \%, 13.30 \%, 5.05 \%$ and $1.33 \%$ were from 20-30, 31-40, 41-50, 51-60, 61-70 and 71-80 years' age group respectively. So the highest portion participants were from 31-60 years' age range. In analyzing the access-related complications we found the highest $1.86 \%$ participants were with port side bleeding and nearest $0.53 \%$ were with Retained stones in port (Sepsis). Then $0.27 \%, 0.53 \%, 0.27 \%$ and another $0.27 \%$ participants were with small bowel laceration, subcutaneous emphysema, small bowel puncture and ascending colon laceration respectively. On the other hand in analyzing procedure-related complications we found the highest $2.13 \%$ participants were with bleeding through cystic artery. Besides this, $0.80 \%$, $0.53 \% 1.60 \%, 0.27 \%$ and $1.86 \%$ participants were with sub-capsular liver hematoma, duodenal perforation, bleeding from Gallbladder bed, colon perforation and stones spillage in peritoneal cavity respectively. Moreover in this study, in total 10 cases were gone into conversion to open cholecystectomy. Those were with duodenal perforation ( 2 of 2), port site bleeding ( 2 of 4 ), bleeding (Cystic artery, 3 of 8), colon perforation (1 of $1)$, small bowel (1 of 1 ) and small bowel puncture (1 of 1). In post-operative complications, we found pyoperitoneum $2(0.53 \%)$ and hemorrhage (Secondary, Reactionary) 4(1.06\%).

Table-I: Age distribution of participants $(\mathrm{N}=376)$

\begin{tabular}{|c|c|c|}
\hline Age (Years) & $\mathbf{n}$ & \% \\
\hline $20-30$ & 27 & 7.18 \\
\hline $31-40$ & 77 & 20.48 \\
\hline $41-50$ & 198 & 52.66 \\
\hline $51-60$ & 50 & 13.30 \\
\hline $61-70$ & 19 & 5.05 \\
\hline $71-80$ & 5 & 1.33 \\
\hline Total & $\mathbf{3 7 6}$ & $\mathbf{1 0 0}$ \\
\hline
\end{tabular}

Table-II: Access-related complications ( $=376)$

\begin{tabular}{|l|c|c|}
\hline Complications & $\mathbf{n}$ & $\mathbf{\%}$ \\
\hline Port site bleeding & 7 & 1.86 \\
\hline Small bowel laceration & 1 & 0.27 \\
\hline Sub-cutaneous emphysema & 1 & 0.27 \\
\hline Retained stones in port (Sepsis) & 2 & 0.53 \\
\hline Small bowel puncture & 1 & 0.27 \\
\hline Ascending colon laceration & 1 & 0.27 \\
\hline
\end{tabular}


Table-III: Procedure-related complications ( $\mathrm{N}=376$ )

\begin{tabular}{|l|c|c|}
\hline Complications & $\mathbf{n}$ & $\mathbf{\%}$ \\
\hline Sub-capsular liver hematoma & 3 & 0.80 \\
\hline Duodenal perforation & 2 & 0.53 \\
\hline Bleeding from Gallbladder bed & 6 & 1.60 \\
\hline Colon perforation & 1 & 0.27 \\
\hline Stones spillage in peritoneal cavity & 7 & 1.86 \\
\hline Bleeding from cystic artery & 8 & 2.13 \\
\hline
\end{tabular}

Table-IV: Conversion to open cholecystectomy and the underlying causes $(\mathrm{N}=376)$

\begin{tabular}{|l|c|c|c|}
\hline Complications & $\mathbf{n}$ & $\begin{array}{c}\text { Conversion } \\
\text { (n) }\end{array}$ & $\mathbf{\%}$ \\
\hline $\begin{array}{l}\text { Duodenal } \\
\text { perforation }\end{array}$ & 2 & 2 & 0.53 \\
\hline Port site bleeding & 4 & 2 & 0.53 \\
\hline $\begin{array}{l}\text { Bleeding (Cystic } \\
\text { artery) }\end{array}$ & 8 & 3 & 0.80 \\
\hline Colon perforation & 1 & 1 & 0.27 \\
\hline Small bowel & 1 & 1 & 0.27 \\
\hline $\begin{array}{l}\text { Small bowel } \\
\text { puncture }\end{array}$ & 1 & 1 & 0.27 \\
\hline
\end{tabular}

Table-V: Post-operative complications of the study participants. $(\mathbf{N}=376)$

\begin{tabular}{|l|c|c|}
\hline Complications & $\mathbf{n}$ & $\mathbf{\%}$ \\
\hline Pyoperitoneum & 2 & 0.53 \\
\hline $\begin{array}{l}\text { Hemorrhage } \\
\text { (Secondary, Reactionary) }\end{array}$ & 4 & 1.06 \\
\hline
\end{tabular}

\section{DISCUSSION}

In this retrospective study the extra-biliary complications were reported either access-related or procedure-related. Access-related complications are common despite various changes made in the access techniques. Hashizume and Sugimachi[9] have reported trocar injuries to bowel and major blood vessels to be as high as $1 \%$ and most of them have occurred during the insertion of the first tocar. Schafer et al.[10] in their study report a similar result. Blind trocar insertion and access by verress needle remain the important causes of complications as reported by many authors. In our practical experience, most common access-related complications were port-site bleeding and extraperitoneal insufflations resulting in surgical emphysema of varying degrees. Direct trauma to superior epigastric vessels can lead to uncontrollable bleeding and ultimate conversion. Gaining access by closed technique has a complication rate in the range of $0.2-0.3 \%$ as reported by Loffler and Pent [11]. On the other hand, open technique of trocar insertion has promising results and seems to have reduced the access-related major vessel injury and mortality rate[12]. Trocar insertion under vision through avascular planes and a thorough inspection of the ports before deflation of the abdomen can reduce port site bleeding. Mayo et al.[13] Subcutaneous emphysema usually occurs due to leakage of gas from the site of trocar insertion and is likely when patient is obese and gas is insufflated through a misdirected Veress needle. This may require manual pressure on abdominal wall to evacuate the gas. This is consistent with other similar studies[14]. Previous operations may make abdominal access difficult and liable to produce bowel injury. On the other hand, access-related bowel injuries were found more common with closed technique of abdominal access. This is similar to results of other similar studies [15]. We report $7.18 \%$ overall procedure-related problems in this series of which a little portion were serious enough to demand conversion to open procedure. Procedure-related complications are more likely to occur when there is history of repeated attacks of acute cholecystitis leading to distortion of anatomy of Calot's triangle. Colonic perforation was another serious procedure-related complication and occurred in two patients, both of which were converted. These procedural injuries to gastrointestinal tract are associated with a high mortality rate as indicated by various studies [16]. The duodenal injuries in our study were caused during difficult dissection in the Calot's triangle. This is consistent with other reports [17] and usually results when dissection is continued in a totally obscured field. Patience, displaying of anatomy and identification of structures before cutting or applying clips are vital to safe outcome. Through this study we observed that major extra-biliary complications are as frequent as the biliary complications and can be lifethreatening. On the other hand an early diagnosis is critical to their management.

\section{Limitations of the study}

This was a single centered study with a small sized sample. So the findings of this study may not reflect the exact scenario of the whole country.

\section{CONCLUSION AND}

\section{RECOMMENDATIONS}

Through this study we observed that major extra-biliary complications are as frequent as the biliary complications and can be life-threatening. On the other hand an early diagnosis is critical to their management. For getting more specific findings we would like to recommend for conducting more studies regarding the same issue with larger sized sample.

\section{REFERENCES}

1. Iqbal J, Ahmed B, Iqbal Q, Rashid A. Laparoscopic V/S open cholecystectomy morbidity comparison. Professional Med J. 2002; 9:226-35.

2. Mcsherry CK. Cholecystectomy: the gold standard. Am J Surg. 1989; 158:174-8.

3. Shamiyeh A, Wayand W. Laparosopic cholecystectomy: Early and late complications and their treatment. Langenbecks Arch Surg. 2004; 389:164-71. 
4. Peters JH, Ellison EC, Innes JT, Liss JL, Nicholas KE, Lomano JM. Safety and efficacy of laparoscopic cholecystectomy: A prospective analysis of 100 initial patients. Ann Surg. 1991; 213:3-12.

5. Victorsdottir O, Bloendal S, Magnusson J. Frequency oof serious complications following laparoscopic cholecystectomy. Laeknabladid. 2004; 90:487-90.

6. Rajdeep S, Robin K, Rajeev SK. Ashok A. Nonbiliary mishaps during laparoscopic cholecystectomy. Indian J Gastroenterol. 2004; 23:47-9.

7. Schoonderwoerd L, Swark DJ. The role of optical access trocars in laparoscopic surgery. Surg Technol Int. 2005; 14:61-7.

8. Fuller J, Ashar BS, Carry-Corrado J. Trocar associated injuries and fatalities: An analysis of 1399 reports to the FDA. J Minim Invasive Gynecol. 2005; 12:302-7.

9. Hashizume M, Sugimachi K. Needle and trocar injury during laparoscopic surgery in Japan. Surg Endosc. 1997; 11:1198-201.

10. Schafer M, Lauper M, Krahenbuhl L. Trocar and veress needle injuries during laparoscopy. Surg Endosc. 2001; 15:275-80.
11. Loffla FD, Pent D. Indications, contraindications and complications of laparoscopy. Obstet Gynecol Surg. 1975; 30:407-27.

12. Voitk A, Rizoli S. Blunt hasson trocar injury: Long intra-abdominal trocar and lean patient: A dangerous combination. J Laparoendosc Adv Surg Tech A. 2001; 11:259-62.

13. Mayol J, Garcia-Aguilar J, Ortiz-Oshiro E, DeDiego Carmona JA, Fernandez-Represa JA. Risks of minimal approach for laparoscopic surgery: Multivariate analysis of morbidity related to umbilical trocar insertion. World $\mathrm{J}$ Surg. 1997; 21:529-33.

14. Orlando R, Palatini P, Lirrusi F. needle and trocar injuries in diagnostic laparoscopy under local anesthesia: What is the true incidence of these complications? J Laparoendosc Adv Surg Tech A. 2003; 13:181-4.

15. Henning $\mathrm{H}$. The Dallas report in laparoscopic complications. Gastrointest Endosc. 1985; 31:104-6.

16. Krebs HB. Intestinal injury in gynecologic surgery: A ten-year experience. Am J Obstet Gynecol. 1986; 155:509-14.

17. Binenbaum SJ, Goldfarb SJ. Inadvertant enterotomy in minimally invasive abdominal surgery. JSLS. 2006; 10:336-40. 